\title{
APRENDIZAGEM AO LONGO DA VIDA E AVALIAÇÃO DO DESEMPENHO PROFISSIONAL
}

\author{
Maria IsABel da CunhA*
}

Recebido: 11 jan. $2011 \quad$ Aprovado: 17 jun. 2011

\begin{abstract}
* Dra. docente e pesquisadora do Programa de Pós-Graduação em Educação da UNISINOS, Porto Alegre, Brasil.E-mail: cunhami@uol.com.br
\end{abstract}

\begin{abstract}
Resumo: O tema da aprendizagem ao longo da vida é analisado numa perspectiva crítica, tencionando os discursos produzidos em sua concepção e formas de produção. Analisa-se a condição histórica e política que contextualiza esse dispositivo e se questiona os pressupostos que os ancoram. Tomamse os conceitos de experiência em Dewey e Anísio Teixeira e, posteriormente em Larrosa, para contrapor a idéia de aprendizagem ao longo da vida, no sentido da acumulação de informações e de competências generalizadoras. Reforça-se a concepção de experiência na sua condição subjetiva como fundante da formação e do desempenho profissional. Em torno de cinco questões geradoras organizam-se argumentos para relacionar aprendizagens, concepção de avaliação, compreensão de formação e desempenho profissional.
\end{abstract}

Palavras-chaves: Aprendizagem ao longo da vida. Experiência. Avaliação. Formação. Desempenho profissional.

\section{LIFELONG LEARNING AND EVALUATION OF PROFESSIONAL PERFORMANCE}

Abstract: The issue of lifelong learning is seen from a critical perspective, tensioning the discourses produced in their conception and production. The historical and political condition in which such mechanism is contextualized is analyzed and the presuppositions in which they stand are questioned. The concept of experience is taken from Dewey and Anísio Teixeira and, furthermore, from Larrosa to oppose the idea of lifelong learning in the sense of the adding up of information and generalized competences. The concept of experience in its subjective condition as founding to professional training and performance is reinforced. About five generating questions organize the arguments to relate learning, concept of evaluation and understanding of professional training and performance.

Key words: Lifelong learning. Experience. Evaluation. Professional training. Professional performance.

Mas será que essa visão é que vem acompanhando os discursos da "aprendizagem ao longo da vida"? Quando começamos a enfatizar essa premissa como parte das preocupações da formação? Que impactos essa condição traz para as estruturas de escolarização? Que estão exigindo da sociedade?

Há muitas décadas incorporamos o valor do que se chamava educação permanente. Sobre ela produziram-se discursos oficias e pedagógicos, sendoimplementados programas que reconheciam a importância e a necessidade de que a formação não fosse apenas entendida como uma etapa pré-profissional, mas que assumisse um papel importante na trajetória de vida e de profissão das pessoas. 
O conceito de educação permanente, nesse contexto, poderia ser compreendido em distintas perspectivas. A mais comum era a que acenava para a ideia de "atualização", com vistas a incorporar na formação do indivíduo os novos aportes da ciência e da tecnologia. O principal objetivo era evitar a defasagem dos saberes fazendo com que as respostas aos desafios do mundo do trabalho fossem as mais efetivas. Nessa perspectiva entendia-se a educação permanente como um processo de acréscimos, na maioria das vezes sem considerar os saberes já consolidados pelos sujeitos. Essa condição, não raramente tornava inócuos os esforços de formação, pois o novo conhecimento, descolado da experiência, pouco contribuía para o seu êxito. Em muitos casos os participantes de programas dessa natureza apreciavam as novas informações, mas, ao voltarem aos seus espaços concretos de vida e trabalho, não conseguiam alterar/aperfeiçoar suas práticas, como previsto. Ou seja, os novos aportes não se transformavam em novas experiências.

Essas considerações indicam que, na base da compreensão da educação permanente e da atual expressão da aprendizagem para toda vida está, certamente, a compreensão do significado da experiência. O sentido do que somos, do que vivemos e do que narramos é que pode estimular uma trajetória de aprendizagens que favoreçam a formação contínua num sentido humano.

A inserção da experiência como elemento de formação vem acompanhando, de forma mais teorizada, o pensamento educacional desde o início do século XX.

O educador brasileiro Anísio Teixeira (1997), inspirado nas ideias revolucionárias de John Dewey produzidas nos anos 20 e 30 do século XX, procurou explicitar a controvertida relação entre filosofia, ciência e educação. Na visão do pragmatismo, tomado por ele como referência, a filosofia não se constituía como um saber apenas especulativo, mas se explicitava em práticas e concepções dos sujeitos situados. Nesse sentido, a filosofia mantém relações com a experiência, pois a noção de verdade é relativa ao tempo, ao lugar, à finalidade e ao resultado das investigações. Para Dewey, em seu clássico estudo Democracia e Educação, de 1916, as teorias educacional e filosófica formavam um mesmo texto e no centro dessa relação está o conceito de experiência, muitas vezes ambíguo nos seus usos e sem merecer uma atenção especial na sua compreensão. Em alguns casos, inspirada na visão platônica, a experiência trata de uma percepção do senso comum que entende a expressão como algo passado e anterior ao conhecimento racional, devendo ser ultrapassada pelas ideias em si. Essa concepção está na base de uma relação teoria - prática que valoriza a teoria sobre a prática, numa percepção dualista que muito tem influenciado os processos de educativos e de formação. Dewey, entretanto ,afirma que é 
fundamental superar essa compreensão dualista, pois, "a dissociação entre as ordens mental e material, teórica e prática, implica uma forte valorização da perspectiva intelectual, teórica, contemplativa, em detrimento da atividade, da prática em ação" (MOREIRA, 2008, p. 183).

As reflexões de Anísio Teixeira procuraram vincular a perspectiva do pragmatismo a uma dimensão política e social, destacando a mudança da compreensão do termo experiência a partir da visão empírica para a visão experimental. No conceito tradicional, experiência refere-se aos saberes que se estabelecem na forma de rotinas, formando um hábitus, quase sempre compreendidos de forma temporal, estruturados pela permanência e repetição. Mas o autor afirma que desde o renascimento, e mais tarde com a contribuição de Bacon, já se conhece uma compreensão distinta, ao ser introduzido o termo experimentação, "algo que juntaria o conhecimento material e teórico" (MOREIRA, p. 184), procurando superar o dualismo sensível-racional, teoria e prática.

Anísio Teixeira, interpretando as ideias do pragmatismo de Dewey, afirma que, nessa perspectiva "a experiência é concebida a partir da interação dos seres entre si, e entre estes e o ambiente, considerando-se os processos de transformação e adaptação dos mesmos" (p. 185), portanto inserida na própria natureza, sendo um dos seus elementos constitutivos.

Em que pesem as críticas que no Brasil, depois dos anos 70, recaíram sobre o pensamento que caracterizou os estudos de John Dewey e Anísio Teixeira, muitas contribuições importantes precisam ser resgatadas, quando se trata de aprendizagens e sua relação com a formação para a vida e para o trabalho. A perspectiva da teoria crítica de origem marxista, apropriada num momento do país de forte reação ao imperialismo americano, produziu importantes análises dos limites da proposta do chamado pragmatismo pedagógico, ligando essa produção a uma condição liberal, centrada no individuo aprendente. Se essa crítica foi importante para diminuir a ingenuidade que pode ter caracterizado o contexto de algumas experiências propostas pelos seguidores de Anísio, ela pecou ao deixar de reconhecer os avanços que as concepções matriciais de seu pensamento trouxeram para a educação brasileira. Sua luta era por uma educação pública, laica e democrática e, como tal, não poderia estar alinhada com uma visão excludente e individualista.

É possível que hoje, passado quase um século da geração do conceito de formação ligado à valorização da subjetividade e da experiência, essa possa se constituir num mote de novas teorizações.

Não casual tem sido o uso das idéias do catalão Jorge Larrosa Bondia (2002) nas pesquisas em educação de nosso país. Há uma especial preferência por um texto em que ele discute a experiência e os saberes da experiência, 
convidando o leitor a olhar o fenômeno numa perspectiva mais existencial e estética a partir do par experiência/sentido.

Propondo-se a explorar o sentido das palavras, Larrosa Bondia afirma crer no poder que elas têm, pois, para ele, não pensamos com pensamentos, mas com palavras. Aplicando essa compreensão, exemplifica que, quando proferimos a palavra "pensar", não nos referimos a "raciocinar ou calcular ou argumentar, como nos tem sido ensinado algumas vezes, mas sobretudo dar sentido ao que somos e ao que nos acontece" (p. 21).

Pois a palavra experiência, para o autor, significa o que nos acontece e não o que acontece. Parece sutil essa diferença na construção linguística, mas faz toda a diferença na percepção do sentido. Pensar a experiência como o que nos acontece, inclui uma mobilização do sujeito atingido pelo que viveu, pelo que o afeta, deixa marcas, produz efeitos genuínos, imprime vestígios.

A palavra experiência vem do latim experiri, provar (experimentar), o mesmo radical que se encontra em periculum, perigo, explica Larrosa Bondia, onde o per indica travessia, passagem. Lembra que a mesma raiz está na palavra peiratês, pirata, incluindo a noção de que o sujeito da experiência assume algo dessa fascinante contingência do desconhecido. Inspirado em Heidegger (1987) explica que fazer uma experiência com algo significa que algo nos acontece, nos tomba e nos transforma. Atinge o sujeito de forma que "sua imagem não é aquela de quem está sempre em pé, ciente de seus sucessos e poderes, mas aquele que perde seus poderes precisamente porque a experiência dele se apodera" (p. 25). Somente o sujeito da experiência está, portanto, aberto à sua própria transformação.

Larrosa Bondia chama atenção, também, para as dificuldades de colocar o homem contemporâneo a viver experiências. Para ele o excesso de informações é uma das causas desse fenômeno, com intensa repercussão para a educação escolarizada. Um estudante pode estar ouvindo aulas, lendo livros, fazendo uma viagem e incorporando informações. Mas nada lhe aconteceu, nada o tocou, nada com ele sucedeu. O ritual de avaliação, na maior parte das vezes, nada mais valoriza do que a reprodução da informação e sua extensão e complexidade.

Para Larrosa Bondia, depois da informação vem a opinião, que se tornou num imperativo para o sujeito moderno. Utiliza as ideias de Benjamim (1991), e afirma que o periodismo é o grande dispositivo moderno que inviabiliza a experiência. Antes de vivê-la, expondo-se às dúvidas às ambiguidades, o sujeito já é instado a formar sua opinião, em geral de forma superficial e com nenhuma responsabilidade com suas repercussões. 
A essa contingência que dificulta a experiência, soma-se a falta de tempo. Tudo acontece em grande velocidade, onde um estímulo logo é substituído por outro sem deixar qualquer vestígio. Essa condição supervaloriza a novidade, o que choca, que agita, mesmo que nada aconteça com os sujeitos envolvidos. Não há tempo para a experiência. $O$ frenesi da valorização do novo se coloca em descompasso com o tempo necessário para a experiência. Essa condição também leva a outro entrave para a vivência da experiência: o excesso de trabalho, que coloca o sujeito moderno constantemente em atividade e, "porque estamos sempre mobilizados, não podemos parar; e, porque não podemos parar, nada nos acontece" (p.24).

Através dos argumentos que sustentam essa crítica compreende-se que "a experiência requer tempo para pensar, analisar, sentir, suspender a opinião, cultivar a atenção, falar sobre o que nos acontece, escutar os outros, ter paciência e dar-se tempo e espaço" (p. 25). Viver uma experiência exige, na visão de Larrosa Bondia, ainda, uma dose de paixão, aquela que cultiva uma responsabilidade em relação ao outro, mesmo sem perder a liberdade e a autonomia. Diz ele:

A paixão funda uma liberdade dependente, determinada, vinculada, obrigada, inclusa, fundada não nela mesma, mas numa aceitação primeira de algo que está fora de mim, de algo que não sou eu e, por isso, justamente, é capaz de me apaixonar (p. 26).

Pareceu-me interessante trazer duas visões de experiência produzidas em tempos distintos e interpretadas em contextos peculiares que definiram as motivações para a produção de sentidos sobre a experiência e, por contingência, para a formação.

Ler Dewey, Anísio e Larrosa Bondia provocou a minha indagação sobre os discursos a respeito da aprendizagem para toda a vida e a avaliação do desempenho profissional. De quais aprendizagens estamos falando? Que concepção de avaliação vem presidindo a compreensão das aprendizagens? Como os parâmetros de avaliação estão incidindo sobre a compreensão de formação? Que relação há entre a formação e o desempenho profissional? Que se compreende como qualidade do desempenho profissional?

As respostas a essas questões são múltiplas. Mas o que fica claro é que não se pode falar em "aprendizagem para toda vida" sem ampliar a reflexão sobre o significado dessa expressão no contexto em que vivemos. Tomo, então, as perguntas provocativas registradas acima, para continuar com a reflexão: 


\section{DE QUAIS APRENDIZAGENS ESTAMOS FALANDO?}

A resposta a essa questão está ligada ao que anteriormente tentei explorar. Se aprendizagem é compreendida numa perspectiva de atualização e inserção na chamada sociedade da informação então teremos de entrar num processo vertiginoso que confronta sempre o sujeito com uma situação de déficite. Tudo indica que nunca estaremos quites com as últimas descobertas da ciência e seus aplicativos e, portanto, somos percebidos em constante desatualização. No mundo laboral, essa categorização incide em situações de desprestígio com as repercussões no emprego e na remuneração. A permanência dessa natureza de discurso tende a provocar um mal estar profissional intenso, culpabilizando o sujeito pela sua incompetência, sem analisar outros condicionantes dessa situação. O caso da categoria docente é um significativo exemplo. O discurso de desqualificação dos professores por não estarem atualizados é permanente e cria uma representação de um desempenho profissional sempre aquém das expectativas, produzindo uma autoimagem frágil. A quem interessa esse discurso? Será ele proposto com o sentido de fortalecer o desejo de formação contínua? Ou estará reforçando a desqualificação para aviltar salários e comprometer as reivindicações profissionais? Serve para fragilizar a legitimidade do campo da educação? Indica uma intenção de controle da profissão pelos oligopólios da indústria editorial?

Por outro lado, é inequívoca a necessidade de aprendizagem permanente para o professor, assim como para qualquer profissional. Mas essa condição parte do reconhecimento do docente como um produtor de saberes, de sujeito das suas próprias aprendizagens, que precisa viver, valorizar e partilhar experiências, ligando-as a uma produção de sentidos.

O exemplo do magistério certamente pode ser aplicado a outras profissões e está exigindo uma reflexão mais sistemática sobre o tema e um envolvimento da sociedade com suas repercussões.

\section{QUE CONCEPÇÃO DE AVALIAÇÃO VEM PRESIDINDO A COMPREENSÃO DA APRENDIZAGEM?}

A substituição na noção de saberes pela de competências trouxe uma visão compartimentada da experiência. Essa não mais é compreendida como uma totalidade, pois a necessidade de explicitar indicadores avaliativos forçou o seu fracionamento. É certo que é difícil avaliar quando há falta de indicadores. Mas é também complexo avaliar a experiência fatiando-a como se um movimento 
de vida não tivesse a ver com o outro. Experiência não se avalia com uma contabilidade de produtos. Algumas vezes os produtos podem estar aquém do esperado e a experiência ser da maior importância, pois aprender também significa pensar sobre o vivido e sobre si.

Outra repercussão da concepção de avaliação sobre a aprendizagem é a que condiciona a experiência a um tempo determinado. Para Readings (2002) "o tempo da educação é ainda considerado, de modo geral, em termos de uma metanarrativa modernista que perdeu a força, como a passagem da ignorância ao esclarecimento, num determinado período". O autor recorre a Freud para afirmar que a educação, como a psicanálise é infensa à terminalidade. Mas, continua sua análise afirmando que, entretanto, "o tempo pedagógico, como algo exaustivamente contábil, é traço marcante do impulso para a excelência" (p. 55). Não desconhecemos que o "tempo de conclusão" vem sendo apresentado como critério de qualidade e eficiência da formação. O autor critica essa visão ferrenhamente e põem em questão a noção de excelência, ainda que defenda a avaliação, sempre que essa se distancia do cálculo estatístico que recusa a relação entre responsabilidade e contabilidade. Também reflete sobre a finalidade da avaliação e seus resultados, quando se trata de melhorar a formação e o desempenho profissional. Defende que os avaliados deveriam conversar entre si e com os outros para que todos compreendam a complexidade do problema da qualidade. Desse modo a avaliação não teria um fim em si mesma, mas alcançaria o importante papel de instaurar uma discussão contínua. Continua Readings afirmando que "se admitimos que quaisquer julgamentos são atos discursivos, podemos compreender a sua complexidade (p. 65)", entendo-os como um juízo a ser avaliado pelos outros, nunca um juízo final. Nesse sentido o efeito do julgamento é entendido mais em relação com a discussão contínua do que com a conclusão.

\section{COMO OS PARÂMETROS DE AVALIAÇÃO ESTÃO INCIDINDO SOBRE A COMPREENSÃO DE FORMAÇÃO?}

A cultura da avaliação tem sido uma das mais recorrentes na contemporaneidade. Mesmo considerando a avaliação como uma prática secular na relação dos homens com o mundo produtivo - em que a escola se constitui num exemplo peculiar - é preciso registrar como essa dimensão do trabalho humano potencializou sua importância, na medida em que as estruturas capitalistas globalizadas se instituíram de forma efetiva. 
A virada epistemológica, que favoreceu a ruptura com os princípios da ciência moderna, favoreceu a compreensão de que os processos de formação são intencionais, incluem a subjetividade dos envolvidos e se instituem em contextos históricos e geográficos definidos. Coerente com esses princípios instalou-se a busca de uma genealogia, não como um fim em si mesma, mas como um ponto principal de referência para fazer avançar o conhecimento e construir teorias que pudessem ajudar a explicação dos fenômenos. Tal perspectiva distanciouse das grandes generalizações porque procurou valorizar tanto as regularidades como as especificidades das construções cotidianas. A cotidianeidade assumiu uma importância significativa na compreensão do mundo e os estudos de Heller (1985) foram uma preciosa ajuda para a construção de pesquisa e da reflexão sistematizada.

Em estudo anterior explorei a idéia de que "esse arcabouço histórico conceitual do entendimento da formação e da mudança paradigmática, que vem afetando a concepção de conhecimento e incluindo novas racionalidades, tem tido importante influência no campo da formação, fragilizando a compreensão do conhecimento profissional, entendido na perspectiva da racionalidade técnica" (CUNHA, 2008).

Schön (1992) reforçou essa ideia indicando três razões. A primeira é de que, quando se assume que o conhecimento profissional possa ser produzido fora da situação em que deve ser aplicado, ignora-se que o conhecimento sempre deve estar "inserido em um contexto socialmente estruturado, compartilhado pela comunidade dos praticantes e exercido através de meios institucionais concretos da profissão" (p. 147).

A segunda razão, apontada pelo autor, se sustenta na impossibilidade concreta de uma aplicação linear entre a teoria e a prática. Os trabalhadores, geralmente, atuam desde a base do conhecimento prático herdado que envolve valores, opções e referências que dão sentido às suas ações concretas.

A terceira razão refere-se ao fato de que os problemas da vida real são únicos e contextualizados e, portanto, não podem ser resolvidos apenas mediante uso de técnicas derivadas da investigação teórica. Schön menciona a necessidade de uma competência artística para encaminhar adequadamente a prática, apelando para outras racionalidades que não apenas as que se baseiam na razão cognitiva instrumental.

A compreensão da formação como produto das condições sociais e históricas recupera o fundamental papel político que a sustenta. Freire (1982) deu significativas contribuições nesse sentido. Defendeu ele que "não há educação fora das sociedades humanas e não há homem no vazio" (p. 35) uma vez que "educação 
é diálogo, na medida em que não é transferência de saber, mas um encontro de sujeitos interlocutores que buscam a significação dos significados" (p. 69).

Se essas posições têm sido aceitas e apreciadas nos espaços acadêmicos e escolarizados, a concepção de formação tem sido também atingida pelas micropolíticas economicistas nacionais e internacionais, que tomam como principal estruturante a relação custo-benefício aplicada às políticas sociais. $\mathrm{E}$ a avaliação se constituiu no principal instrumento indutor de racionalidades que se afastam das compreensões que vinham, paulatinamente, dando suporte as narrativas e práticas da formação.

Quando as palavras-chave começam a se explicitar como competência, excelência e produtividade de uma forma generalizada, a formação é seriamente atingida, pois a ênfase nos resultados finais de produção afasta-se da consideração das ricas cadeias de mediação e do processo histórico de sua produção que explicitam escores finais.

Esse posicionamento crítico não quer e não pode ser argumento que se contraponha a todo e qualquer processo avaliativo. Ao contrário, precisa revelar uma preocupação com uma cultura avaliativa sistemática e processual, que traga elementos significativos para a melhoria da qualidade da formação e do desempenho profissional. A grande questão é definir a que qualidade da formação nos referimos e que indicadores poderiam balizar os processos avaliativos que se contraponham ao reducionismo dos produtos. Nessa perspectiva, o conceito de formação precederia a construção do parâmetro avaliativo e, principalmente, definiria, do ponto de vista político, o conteúdo e a forma da avaliação.

\section{QUE RELAÇÃO HÁ ENTRE A FORMAÇÃO E O DESEMPENHO PROFISSIONAL?}

Por muitas décadas entendíamos a formação como uma preparação préprofissional, especialmente de responsabilidade dos sistemas formais de educação. Havia uma compreensão de que a teoria proveniente de um campo de conhecimento seria capaz de orientar as ações da prática. Muitas dessas formações escolares e acadêmicas não previam qualquer inserção no mundo laboral e nesses ambientes se instalava, veladamente, uma compreensão da menos valia dos saberes profissionais produzidos em terreno.

Esse modelo de formação estribava-se num currículo que privilegiava uma visão epistemológica no mesmo sentido: a teoria é que produz a prática. $\mathrm{Na}$ melhor das hipóteses, os currículos incorporavam a modalidade final de estágios. Mas esses não eram concebidos como fontes de aprendizagem e sim de aplica- 
ção dos conhecimentos teóricos. Ao acompanhar estudantes nessa experiência o formador pretendia observar se, na prática, os estudantes aplicavam a teoria que haviam aprendido anteriormente.

Essa condição quase sempre revelava inadequações significativas. Os estudantes viviam um choque de realidade, pois a prática era muito mais complexa e situada do que imaginavam. E os formadores passavam por um processo de frustração que redundava numa culpabilidade da proposta curricular ou da incapacidade dos estudantes de se apropriarem adequadamente da teoria.

A ruptura epistemológica - já mencionada neste texto - que se explicitou nas últimas décadas, evidenciou a inadequação dessas concepções e modelo de formação. Ao compreender o conhecimento como cultural e historicamente situado, incorporou a subjetividade e a complexidade como valor. Nesse sentido, compreendeu o ciclo de formação de maneira distinta, onde a prática é fonte de saberes e da condição de significar a teoria.

Essa concepção de formação inverteu a relação teoria-prática e colocou a condição objetiva de vida do sujeito, seus saberes e experiências como ponto de partida da aprendizagem profissional, uma vez que as dúvidas epistêmicas nascem da leitura da prática e só então apelam para a teoria como fonte inesgotável de compreensão.

O delineamento curricular dos cursos de formação, a partir dessas compreensões, iniciou uma significativa mudança, incluindo maior tempo de prática na formação pré-profissional, antecipando esses tempos e diluindo-os no percurso de formação. Os estudos sobre essas alterações conceituais ainda indicam dificuldades para a sua plena implantação, decorrentes de lógicas tradicionais e de culturas instituídas, nem sempre de fácil superação. Mesmo assim, é impossível, hoje, afirmar desconhecimento da crítica aos currículos tradicionais e das reflexões sobre seus impactos na lógica da formação.

Outra condição que vem sendo superada estribava-se na expectativa de que a formação inicial fosse capaz de alcançar as plenas habilidades profissionais, com duração permanente. $\mathrm{O}$ mesmo paradigma que explicitou a prática e o espaço de trabalho como fonte de conhecimento, indicou a compreensão de que as aprendizagens acompanham o homem cognoscente por toda a vida e que a condição da reflexão contínua sobre suas práticas é que podem favorecer a expectativa de experiência, assumida na perspectiva defendida nesse texto.

A expressão "aprendizagem ao longo da vida" corrobora essa compreensão. Se a formação inicial se constitui numa importante base da escolha profissional, não há dúvidas de que ela é uma formação de raiz e que precisa assim ser compreendida na transitoriedade da vida dos sujeitos. 
Para favorecer essa perspectiva temos nos debruçado na explicitação de alguns termos que acompanham a evolução conceitual vivida no contexto da formação. Usando novamente a contribuição de Larrosa Bondia (2002) é preciso assumir que as palavras "funcionam como potentes mecanismos de subjetivação" (p. 21).

Nesse caso, vimos substituindo a palavra profissionalização por profissionalidade, ambas derivadas de profissão. Garcia (1995) afirma que o termo profissão marca diferenças qualitativas com respeito ao ofício, à ocupação e ao emprego. Essa condição favorece o uso da palavra profissional para referir grupos de pessoas com uma elevada preparação, competência e especialização. Popkewitz (1988) acrescenta que essa condição proporciona privilégio, autoridade e reconhecimento social das pessoas que a exercem. A observação desse autor se instala no sentido de salientar "que o conceito de profissão se relaciona com a estrutura de poder da sociedade e é ela, muitas vezes, que caracteriza os indivíduos". Comento, então que, dessa

forma, a profissionalização é um processo histórico e evolutivo que acontece na teia das relações sociais e refere-se ao conjunto de procedimentos que são validados como próprios de um grupos profissional, no interior de uma estrutura de poder. Isso significa admitir que sua configuração ou extinção resulta de lutas concorrenciais que se instalam nos espaços de produção e nos espaços de conhecimento (CUNHA, 1999).

Já a profissionalidade, tomando as palavras de Gimento Sacristan (1993), pode ser percebida como a expressão da especificidade da atuação dos profissionais na prática, isto é, o conjunto de atuações, destrezas, conhecimentos, atitudes, valores ligados a ela, que constituem o específico da profissão. Evidencia-se, nessa conceituação, que a profissionalidade contempla muito mais a subjetividade do sujeito inserido na prática profissional; trata dele enquanto um sujeito histórico, exercendo uma tarefa e/ou uma profissão. Poder-se-ia dizer que a profissionalidade é a profissão em ação.

Essas são reflexões que podem contribuir para aprofundar as relações entre formação e desempenho profissional. É certo que o conhecimento da estrutura de poder, que hierarquiza e controla as profissões, têm importante impacto na profissionalidade. Mas também é compreensível que a profissionalidade pode construir a profissão sempre que se considera a legitimidade dos saberes produzidos no contexto cultural dos sujeitos. 


\section{QUE SE COMPREENDE COMO QUALIDADE DO DESEMPENHO PROFISSIONAL?}

A resposta e esta questão pode ser simples ou pode ser complexa, dependendo dos parâmetros que se toma como referentes. No âmbito das reflexões sobre a educação, ouvimos freqüentemente as expressões "para uma educação de qualidade" e/ou "uma instituição de ensino por excelência". Essas expressões parecem abarcar inúmeras categorias, intenções, desejos, crenças, que dispensam explicações. Falar em educação ou formaçãode qualidade parece não exigir complemento, pois o termo "qualidade" assim como "excelência", aponta para o máximo, para o melhor. Uma expressão incomparável onde qualquer definição se mostraria mais restrita do que a intenção do próprio termo.

Analisando a condição etimológica do termo qualidade, encontramos que ela vem do latim qualitate, que significa "propriedade, atributo ou condição das coisas ou pessoas capaz de distingui-las das outras e de lhes determinar a natureza" (FERREIRA, 1975, p. 1175). O conceito de qualidade é multidimensional, o que torna complexo definir seu significado. A sua compreensão incorpora uma dimensão ética e estética e, principalmente, uma dimensão axiológica. Rios (2000) chama a atenção para o fato de que o termo qualidade já carrega em sua compreensão uma ideia de algo bom, contrapondo-se a noção de defeitos, incompletude (p. 68). Entretanto, pela definição etimológica essa condição não tem sustentação. Qualidade não é uma adjetivação que remete a um construto universal, mas são propriedades que se encontram nos seres, ações ou nos objetos. Ao atribuir qualidade a algo ou a um fenômeno estamos explicitando um valor, assim como quando dizemos que algo é belo ou adequado. Há, nessas expressões, uma concepção anterior que assume uma condição valorativa e que está ligada ao plano da moral e da condição política do homem. Essa perspectiva significa que a qualidade é auto referenciada; pressupõe um sujeito ou uma comunidade que aceita determinados padrões como desejáveis. Para que se possa definir qualidade, é preciso primeiro explicitar o sentido da ação e a dimensão sobre a qual se estabelece sua intencionalidade.

Muitas vezes a possibilidade definidora da qualidade é expressa por seus produtos. Em alguns casos torna-se necessário um processo de quantificação para tornar objetivo o critério usado para definir e avaliar a qualidade. Certamente a quantidade pode ser um atributo da qualidade. Entretanto nem sempre a relação é tão linear. Quando a qualidade se expressa em processos, os produtos se tornam relativos e a dimensão da qualidade exige outras formas de expressão, especialmente as que conseguem transmitir o significado da ação, o sentido que ela pode ter para alguém ou para um coletivo. 
Essas compreensões se aplicam, certamente, ao desempenho profissional. Há um jogo de expectativas que se consubstanciam em padrões, muitas vezes em tensão. No decorrer deste texto procuramos explicitá-las desde que tomamos o conceito de experiência como fundante da formação. Mas certamente essa não é uma visão hegemônica e sequer preponderante na cultura que nos instituiu. Servem estas reflexões como uma provocação para análise dos processos de formação e avaliação que implementamos.

Que rumos seguir? Como pautar nossa ação de intelectuais militantes por um mundo mais humanizado? Essas são questões que exigem posicionamentos dos educadores e cidadãos comprometidos com seu tempo. Mas certamente vão exigir esforços conjuntos e capacidade argumentativa que rivalize com as proposições da economia de resultados, instalada pela perspectiva neoliberal.

Cabe a cada um de nós tomar posições e ao nosso coletivo a capacidade de reação, refletindo e fazendo avançar experiência alternativas mobilizadoras para, como a afirma Sousa Santos (2010) alcançar uma "ecologia dos saberes".

Essas são conjuntos de práticas que promovem uma nova convivência ativa de saberes no pressuposto de que todos eles, incluindo o saber científico, se podem enriquecer com o diálogo com os conhecimentos práticos considerados úteis. Para tal são necessárias comunidades epistêmicas mais amplas que convertam os espaços de formação em espaço público de inter-conhecimento, onde os cidadãos e os grupos sociais possam intervir sem ser exclusivamente na posição de aprendizes (p. 77).

Estaremos aptos a enfrentar esse desafio?

\section{REFERÊNCIAS}

BENJAMIN, Walter. Para una crítica de la violência y otros ensaios. Madrid, Taurus, 1991.

CUNHA, Maria Isabel da.Profissionalização docente: contradições e perspectivas. In: VEIGA, Ilma Passos de A.; CUNHA, Maria Isabel da (Orgs.). Desmistificando a profissionalização docente. Campinas:Papirus, 1999.

. (Org.). Formatos avaliativos e concepção de docência. São Paulo: Autores Associados, 2005.

CUNHA, Maria Isabel da. Impasses contemporâneos para a pedagogia universitária: implicações para os currículos e a prática pedagógica. In: 
COLÓQUIO LUSO-BRASILEIRO SOBRE QUESTÕES CURRICULARES, 4, 2008, Porto, Portugal. 1 CD-ROM.

FERREIRA, A. B. H. Novo dicionário da língua portuguesa. Rio de Janeiro, RJ: Nova Fronteira, 1975.

FREIRE, Paulo. Ação cultural para a liberdade e outros escritos. Rio de Janeiro: Paz e Terra, 1982.

GARCIA, Carlos Marcelo. Constantes y desafios actuales de laprofesión docente. Revista de Educación, Madrid, n. 306, p. 53-67, 1995.

GIMENO SACRISTAN, José. Conciencia y acción sobre lapráctica como liberaciónprofesional. In: IBERNON, Francisco (Coord.).La formación permanente del professorado em los países de La CEE. Barcelona: ICE Universidade de Barcelona-Horsori, 1993. p. 53-92. HEIDEGGER, Martin. De caminoalabla. Barcelona: Del Serbal, 1987. HELLER, Agnes.O cotidiano e a história. São Paulo: Paz e Terra, 1985. LARROSA BONDIA, Jorge. Notas sobre a experiência e o saber de experiência. Revista Brasileira de Educação.ANPed, Rio de Janeiro, n. 19, p. 19-28, jan./fev./mar./abr. 2002.

MOREIRA, Carlos Otávio Fiúza. Notas sobre o pragmatismo. In: BRANDÃO, Zaia; MENDONÇA, Ana Waleska. Uma tradição esquecida. Porque não lemos Anísio Teixeira? Rio de Janeiro: Forma \& Ação Ltda, 2008.

POPKEWITZ, T. Ideologia y formación social delprofesorado. Profesionalización y interesessociales. Revista de Educacíon, Madrid, n. 285, p. 125-148, 1988.

READINGS, Bill. Universidade sem cultura? Rio de Janeiro: UERJ, 2002.

RIOS, Teresinha A. Por uma docência da melhor qualidade. Tese (Doutorado) - Faculdade de Educação, Universidade de São Paulo, São Paulo, 2000.

SCHÖN, Donald. Formación de profesionales reflexivos. Barcelona: Paidos Ibérica, 1992.

SOUSA SANTOS, Boaventura de. A Universidade no século XXI: para uma reforma democrática e emancipatória da Universidade. São Paulo: Cortez, 2010. 